\title{
Manufacturing in Flow Shop and Assembly Line Structure
}

\author{
W. Grzechca
}

\begin{abstract}
Product modularity has become an important issue. It allows producing different products through combination of standard components. One of the characteristics of modular products is that they share the same assembly structure for many assembly operations. The special structure of modular products provides challenges and opportunities for operational design of assembly lines. In this paper, an approach for design of assembly lines for modular products is proposed. This approach divides the assembly line into two parts: a subassembly line for basic assembly operations and a production structure for variant assembly operations. The design of the subassembly line for basic operations can be viewed as a single product assembly line balancing problem and be solved by existing line balancing methods. The subassembly line for the variant operations is designed as a flow shop structure and is sequenced with Johnson's algorithm for $\mathbf{2}$ machines case and heuristic methods for $M$ machines case. A final result of tasks assigning to the complex production structure is given and a quality of final solutions is discussed.
\end{abstract}

Index Terms-Assembly lines, heuristic methods, flow shop structure, estimation of final results.

\section{Assembly line BALANCING Problem}

Since always people created new items for their own needs and if these appeared to be helpful they tried both to improve them and manufacture them faster. In order to balance supply and demand the development of technology was a must. Definition of production can be therefore understood as transforming raw materials into a complete valuable product. This transformation combines various tasks of human work, automation and technology. It consists of steps after which the temporary product is closer to the final state. All these processes combined together define the assembly line which formal definition states: Industrial arrangement of machines, equipment, and workers for continuous flow of workpieces in mass-production operations. An assembly line is designed by determining the sequences of operations for manufacture of each component as well as the final product. Each movement of material is made as simple and short as possible, with no cross flow or backtracking. Work assignments, numbers of machines, and production rates are programmed so that all operations performed along the line are compatible. Automated assembly lines consist entirely of machines run by other machines and are used in such continuous-process industries as petroleum refining and chemical manufacture and in many modern engine plants. Although it does not seem difficult by the definition it is a complex field of research.

More than 100 years ago the idea of assembly line was

Manuscript received February 1, 2015; revised July 15, 2015.

W. Grzechca is with Silesian University of Technology, Poland (e-mail: waldemar.grzechca@polsl.pl). introduced in Ford factory in Detroit. It was designed to be an efficient, highly productive way of manufacturing a particular product. Now in XXI century this way of assembly of final products is still very common and we can find it in many companies over the world. The basic assembly line consists of a set of workstations arranged in a linear fashion, with each station connected by a material handling device (transfer lines, roller conveyors, cranes etc.). The components are processed depending on set of tasks and they are performed at each station during a fixed period called as cycle time. The time it takes to complete a task at each workstation is known as the process time [1]. The cycle time of an assembly line is predetermined by a desired production rate. This production rate is set so that the desired amount of end product is produced within a certain time period [2]. In order for the assembly line to maintain a certain production rate, the sum of the processing times at each station must not exceed the stations' cycle time. If the sum of the processing times within a station is less than the cycle time, idle (delay) time is said to be present at that station [3]. One of the main issues concerning the development of an assembly line is how to arrange the tasks to be performed. The tasks are allocated to workstations according to known precedence relationships (very often in form of precedence graph) and specific restrictions which aim to optimize one or more objectives. A feasible assignment of tasks to workstations should guarantee that the following constraints: (1) each task must be assigned to exactly one workstation, (2) all precedence relationships among tasks must be satisfied and (3) the total process time of all the tasks assigned to a workstation cannot exceed the cycle time. The problem of assigning tasks to workstations in such a way that some objectives are optimized is called assembly line balancing problem - ALBP. We can recognize generally two types of ALBP - minimizing number of workstations for a given cycle time (TYPE 1 of ALBP) or minimizing the cycle time for a given number of workstations (TYPE 2 of ALBP). The assembly line balancing problem (ALBP) originated with the invention of the assembly line. Helgeson et al. [4] were the first to propose the ALBP, and Salveson [5] was the first to publish the problem in its mathematical form. However, during the first forty years of the assembly line's existence, only trial-and-error methods were used to balance the lines. Since then, there have been numerous methods developed to solve the different forms of the ALBP. Salveson [5] provided the first mathematical attempt by solving the problem as a linear program. Gutjahr and Nemhauser [6] showed that the ALBP problem falls into the class of NP-hard combinatorial optimization problems. This means that an optimal solution is not guaranteed for problems of significant size. Therefore, heuristic methods have become the most popular techniques for solving the problem. But we should underline that many studies on assembly line including exact solution methods and 
heuristics have been reported in the literature. The detailed reviews of such studies are given by Baybars [2], Erel and Sarin [3], and Scholl and Becker [7]. In the literature assembly line is classified as: straight assembly line, assembly line with parallel stations, U-shaped assembly line or two-sided assembly line. Other classification takes into account number of products which are produced on the line (single model line, multi-model line and mixed-model line).

\section{ASSEMBLy LiNE STRUCTURES}

There exists also a classification regarding plant layout which is used to describe the arrangement of physical facilities in a production plant [8]. Five types of layout can be distinguished:

- serial lines,

- U-shaped lines,

- parallel lines,

- parallel stations,

- two-sided lines.

\section{A. Serial (Single) Lines}

This is a very basic layout of a flow line production system (Fig. 1). It is determined by the flow of materials. It is mostly used for small size products. These lines have several disadvantages:

- monotone work,

- sensibility due to failures,

- inflexibility due to changing demand rates.

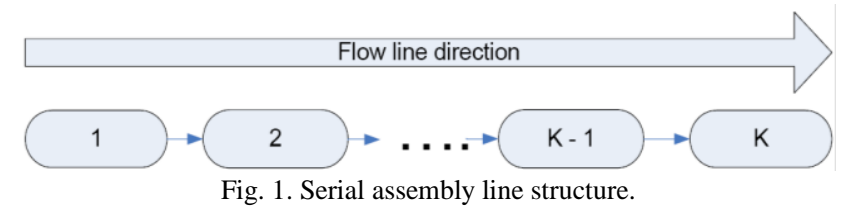

\section{B. U-Shaped Lines}

In order to deal with the problems of a serial line it was redesigned to a form of U-shape (Fig. 2). In such a line operators can work at more than one station simultaneously. For example first operator may both load and unload product units. As they are included in more tasks during production process they are gaining very important experience and enlarge horizons. It is very helpful in case of just-in-time production systems as it improves flexibility which is crucial in dynamically changing demand rates. What more, stations are closer together what results in better communication between operators and in case of emergency they are able to help each other effectively.

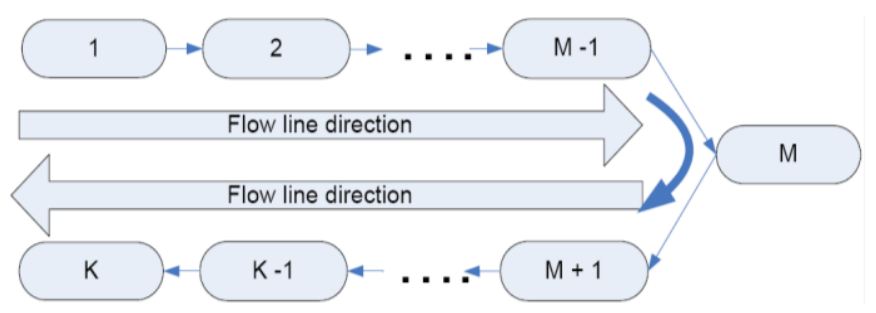

Fig. 2. U-Shaped assembly line structure.

\section{Parallel Lines}

In order to deal with problems described in case of a serial line it might be a good idea to create several lines doing the same or similar tasks (Fig. 3).

The advantages of such a solution [9], [10]:

- increased flexibility for mixed-model systems,

- flexibility due to changing demand rates,

- lowered risk of machine breakdown stopping the whole production,

- cycle time can be more flexibly chosen which leads to more feasible solutions.

The optimal number of lines is however a subject of discussion for every single case separately.

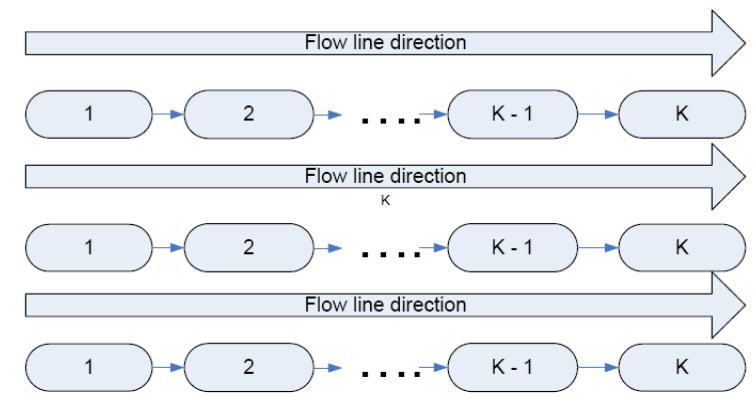

Fig. 3. Parallel assembly lines structures.

\section{Parallel Stations}

As an extension of serial lines bottlenecks are replaced with parallel stations (Fig. 4). Tasks performed on parallel stations are the same and throughput is this way increased [11]-[14].

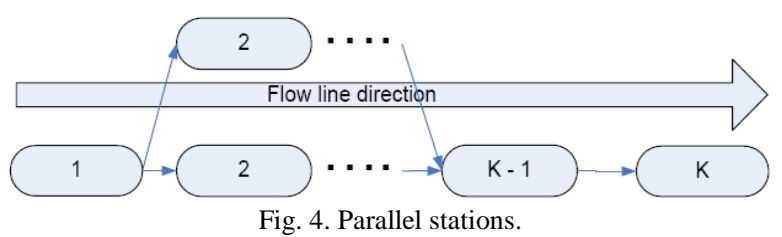

\section{E. Two-Sided Lines}

This kind of flow lines is mainly used in case of heavy workpieces when it is more convenient to operate on both sides of a workpiece rather than rotating it. Instead of single working-place, there are pairs of two directly facing stations such as 1 and 2 (Fig. 5) Such a solution makes the line much more flexible as the workpiece can be accessed either from left or right [15]-[19]. In comparison to serial lines:

- it can shorten the line length,

- reduce unnecessary work reaching to the other side of the workpiece.

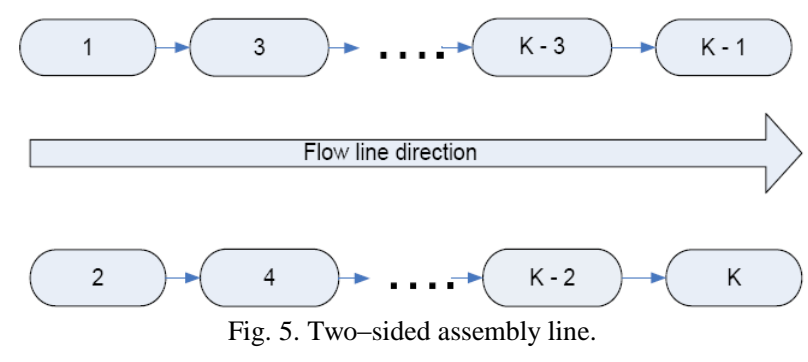

\section{FLOW AND JOB SHOP STRUCTURES}

In many manufacturing and assembly facilities each job has to undergo a series of operations. Often, these operations have to be done on all jobs in the same order implying that the jobs 
have to follow the same route. The machines are then assumed to be set up in series and the environment is referred to as a flow shop. The storage or buffer capacities in between successive machines may sometimes be, for all practical purposes, unlimited. In [20] a detailed description of complex structure of assembly line and flow shop structure is given. Authors developed an approach for designing production structure where modular components are assembled. In the section 5 of this paper a method of balancing and sequencing of complex system which includes assembly line structure and flow shop structure is presented. In some companies when the products that are being processed are physically small or medium the production process is divided in two stages: first the tasks are handled in assembly line, then semi products are moved to buffers and in the second stage there are finished in flow shop environment (Fig. 6). In some cases the production process starts first in flow shop environment and then is finished in assembly line structure (Fig. 7). The two approaches will be discussed.

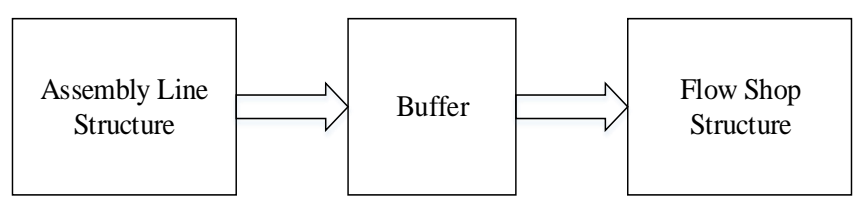

Fig. 6. Assembly line - flow shop structure.

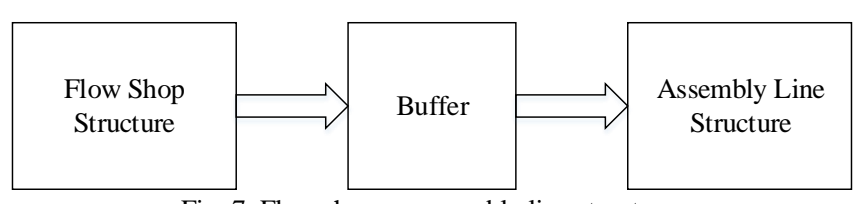

Fig. 7. Flow shop — assembly line structure.

To obtain a balance of assembly line different heuristic methods are presented in the literature (Ranked Positional Weight method, Immediate Update First Fit methods which consider operations processing times WET, precedence graph with number of followers NOF or predecessors NOP, Hofmann Matrix method, Kilbridge \& Wester's method, Moodie \& Young method, etc.) [21]. In the section with numerical example above mentioned methods are considered. The ranked positional method was developed by Halgeson and Birnie [4]. This method assigns those jobs first whose followers have the largest total time. The positional weight of work element is its own processing time plus the processing time of all the following work elements. In RPW as stated earlier, the work element with the highest positional weight is selected and assigned to the current workstation. Similar in NOP or NOF heuristics the number of predecessors or followers is calculated and the tasks with higher score are located in the top of the priority list. Kilbridge and Wester [22] proposed a heuristic $(\mathrm{K} \& \mathrm{~W})$ that selects tasks for assignment to workstations according to their position in the precedence diagram. The procedure presented by Hofmann leads to line balances by operation on a matrix of zeros and ones called a "Precedence Matrix". In flow shop scheduling problem the minimum value of makespan for 2 machines problem is calculated with Johnson's algorithm [23]. Unfortunately the algorithm cannot be generalized to characterize optimal schedules for flow shops with more than 2 machines. For more than 2 machines the minimizing of makespan can be formulated as a mixed integer program. Very often to find any solutions (quick but not optimal) different heuristic methods are used.

\section{MEASURES OF BALANCE QUALITY}

Some measures of solution quality have appeared in line balancing problem. Below are presented three of them [2], [7].

Line Efficiency $(L E)$ shows the percentage utilization of the line. It is expressed as ratio of total station time to the cycle time multiplied by the number of workstations:

$$
L E=\frac{\sum_{i=1}^{K} S T_{i}}{c \times k} \times 100 \%
$$

where $K$ - total number of workstations, $c$-cycle time.

Smoothness index $(S I)$ describes relative smoothness for a given assembly line balance. Perfect balance is indicated by smoothness index 0 . This index is calculated in the following manner:

$$
S I=\sqrt{\sum_{i=1}^{K}\left(S T_{\max }-S T_{i}\right)^{2}}
$$

where $S T_{\max }$ - maximum station time (in most cases cycle time), $S T_{i}-$ station time of station $i$.

Time of the Line $(L T)$ describes the period of time which is need for the product to be completed on an assembly line:

$$
L T=c \times(K-1)+T_{K}
$$

where $c$ - cycle time, $K$ - total number of workstations, $T_{k}-$ load time of the last station.

\section{NUMERICAL EXAMPLE}

We consider an example of manufacturing a final product in complex production system - single assembly line plus flow shop system which consists of unknown number of machines (it is calculated during the balance procedure) for production line and 2 machines for flow shop structure (MI, MII). In the second step we change the configuration: first we schedule flow shop system of 2 machines and then we will finish our process in single assembly line. As an input data we know the precedence graph of our product (Fig. 8) which is necessary for assembly line balancing calculations and the duration times on MI and MII of task in flow shop system for 4 different variants of final products. Below in Table I processing times of assembly operations are given. Table II consists of input data of flow shop system. Because we consider 2 machines system in flow shop structure, the Johnson's algorithm can be implemented and the obtained makespan for this case is optimal. For more number of machines other heuristic methods can be useful. Very often 
the Johnson's rule is considered what means all machines have the same order of tasks.

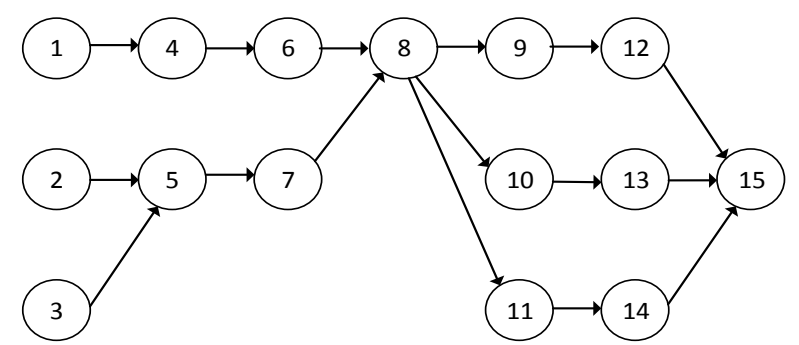

Fig. 8. Precedence graph of an illustrative example.

TABLE I: PROCESSING TIMES OF ASSEMBLY LINE

\begin{tabular}{|c|c|c|c|c|c|}
\hline Task $i$ & time & Task $i$ & time & Task $i$ & time \\
\hline 1 & 4 & 6 & 6 & 11 & 6 \\
\hline 2 & 3 & 7 & 4 & 12 & 7 \\
\hline 3 & 7 & 8 & 5 & 13 & 3 \\
\hline 4 & 2 & 9 & 3 & 14 & 1 \\
\hline 5 & 1 & 10 & 1 & 15 & 1 \\
\hline
\end{tabular}

TABLE II: INPUT DATA OF FLOW SHOP STRUCTURE

\begin{tabular}{|c|l|l|}
\hline & \multicolumn{2}{|c|}{ Machine } \\
\hline Variant $j$ & \multicolumn{1}{|c|}{ MI } & \multicolumn{1}{|c|}{ MII } \\
\hline \multirow{2}{*}{1} & $O 1(2)-O 2(4)-O 3(5)-$ & $O 1(0)-O 2(3)-O 3(7)-$ \\
& $O 4(2)-O 5(1)$ & $O 4(1)-O 5(4)$ \\
\hline \multirow{2}{*}{2} & $O 1(5)-O 2(8)-O 3(1)-$ & $O 1(2)-O 2(6)-O 3(5)-$ \\
& $O 4(0)-O 5(5)$ & $O 4(2)-O 5(0)$ \\
\hline \multirow{2}{*}{3} & $O 1(4)-O 2(3)-O 3(5)-$ & $O 1(0)-O 2(2)-O 3(5)-$ \\
& $O 4(2)-O 5(1)$ & $O 4(1)-O 5(0)$ \\
\hline \multirow{2}{*}{4} & $O 1(3)-O 2(4)-O 3(4)-$ & $O 1(2)-O 2(6)-O 3(5)-$ \\
& $O 4(2)-O 5(1)$ & $O 4(1)-O 5(1)$ \\
\hline
\end{tabular}

where $\operatorname{Oi}\left(t_{i}\right)$ means operation number $i$ with duration time $t_{i}$.

The goal of our calculations is the find a feasible assignment of our tasks in flow shop structure and assembly line structure. First the makespan of flow shop structure for all 4 variants should be calculated. To find the balance of assembly line for unknown number of workstations we calculated the balance for cycle time $c=\max C_{\max }$ (Table III).

TABLE III: MAKESPAN OF DIFFERENT VARIANTS FOR 2 MACHINES FLOW SHOP STRUCTURE

\begin{tabular}{|l|c|c|c|c|}
\hline Variant $j$ & 1 & 2 & 3 & 4 \\
\hline$C_{\max }$ & 17 & 19 & 15 & 19 \\
\hline
\end{tabular}

As we can notice the highest makespan obtained from the Johnson's algorithm is $C_{\max }=19$ and the value is an input cycle time for calculating the assembly line balance. Table IV contains different values of smoothness index, line time and line efficiency which were calculated with different assembly line balancing heuristics. Some results differ from each other and we can choose the most appropriate solution. Because we choose $C_{\max }=19$ some final semi products (variant 1 and variant 3) are assembled earlier and therefore they wait in buffer for starting the assembly process in production line. In the next stage we consider a complex manufacturing system where first stage of production begins in assembly line structure and the second stage of handling is flow shop structure.

Because we consider 4 variants of final products and the basic precedence graph is still the same our calculations are very similar to the steps discussed above. The cycle time of assembly line is connected with the makespan of flow shop structure. For the input date presented in section 5 the value of makespan differs from 15 to 19. Our goal is to avoid waiting times for production process in the buffer and to assure the minimum value of idle times on the machines we discuss now an assembly line - flow shop structure for cycle time equal to the makespan for each variant (in our case $c=15, c=17$ and $c=19$ ), shown in Table V.

TABLE IV: ASSEMBLy LINE MEASURES FOR DIFFERENT HEURISTIC SOLUTIONS

\begin{tabular}{|c|c|c|c|}
\hline Cycle $c$ & \multicolumn{3}{|c|}{19} \\
\hline Heuristic & SI & LE $\%$ & LT \\
\hline RPW & 6 & 89,47 & 51 \\
\hline Hofmann & 6 & 89,47 & 51 \\
\hline K \& W & 3 & 89,47 & 56 \\
\hline M \&Y & 3 & 89,47 & 56 \\
\hline NOF & 3 & 89,47 & 53 \\
\hline NOP & 3 & 89,47 & 53 \\
\hline WET & 6 & 89,47 & 51 \\
\hline
\end{tabular}

TABLE V: ASSEMBly LiNE MEASURES FOR DifFERENT HEURISTIC SOLUTIONS

\begin{tabular}{|c|c|c|c|}
\hline Cycle $c$ & \multicolumn{3}{|c|}{15} \\
\hline Heuristic & SI & LE \% & LT \\
\hline RPW & 7,14 & 85 & 53 \\
\hline Hofmann & 7,28 & 85 & 53 \\
\hline K \& W & 7,14 & 85 & 53 \\
\hline M \&Y & 7,14 & 85 & 53 \\
\hline NOF & 7,14 & 85 & 53 \\
\hline NOP & 7,14 & 85 & 53 \\
\hline WET & 7,14 & 85 & 53 \\
\hline Cycle $c$ & \multicolumn{3}{|c|}{17} \\
\hline Heuristic & SI & LE \% & LT \\
\hline RPW & 13,38 & 75 & 55 \\
\hline Hofmann & 16,03 & 75 & 52 \\
\hline $\mathrm{K} \& \mathrm{~W}$ & 13,38 & 75 & 55 \\
\hline M \&Y & 13,38 & 75 & 55 \\
\hline NOF & 13,38 & 75 & 55 \\
\hline NOP & 13,38 & 75 & 55 \\
\hline WET & 13,38 & 75 & 55 \\
\hline Cycle $c$ & \multicolumn{3}{|c|}{19} \\
\hline Heuristic & SI & LE \% & LT \\
\hline RPW & 6 & 89,47 & 51 \\
\hline Hofmann & 6 & 89,47 & 51 \\
\hline K \& W & 3 & 89,47 & 56 \\
\hline M \&Y & 3 & 89,47 & 56 \\
\hline NOF & 3 & 89,47 & 53 \\
\hline NOP & 3 & 89,47 & 53 \\
\hline WET & 6 & 89,47 & 51 \\
\hline
\end{tabular}

As we can notice the line time is the less sensitive for changing the value the value of cycle time. But the efficiency line give us the knowledge about the utilization of machines. The smoothness index includes the information about time gaps in the assembly system. Taking into account this all knowledge it is obvious that the best result is when cycle time is equal to the makespan $C_{\max }=19$. In the Fig. 9 the solution of assembly line balancing process obtained with NOF heuristic is presented.

Additionally, we can estimate the waste time in the buffer for a given market demand. Examples of market demand and waste time (waiting time) in the buffer are given in Table VI. The order of variant's manufacturing is: 1-2-3-4.

The total waiting time is calculated as amount of variant demand multiply the difference of $C_{\max }$ and the current variant's makespan. To improve the flow of assembly line we can change the cycle time from $c=19$ to $c=18$. Fig. 10 presents the load time of each station for the changed cycle value. 


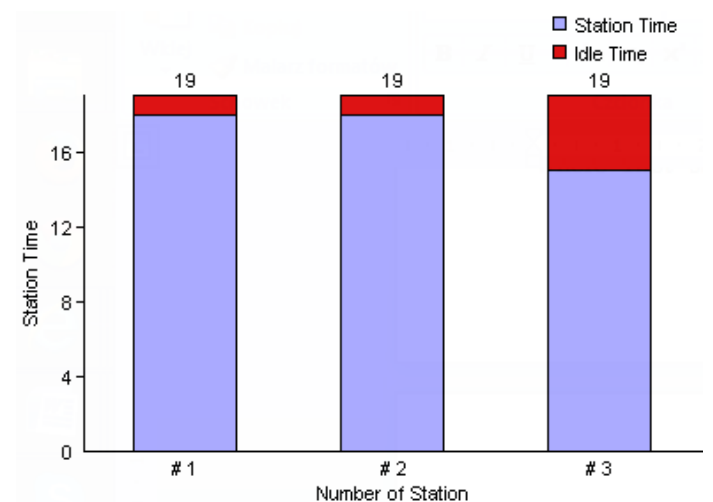

Fig. 9. Load time of each station for $c=19$ and NOF heuristic.

TABLE VI: VARIANT'S MARKET DEMAND AND TOTAL WAITING TIME FOR CYCLE TIME $C=19$ AND VARIANT'S ORDER 1-2-3-4

\begin{tabular}{l} 
CYCLE TIME $C=19$ AND VARIANT'S ORDER 1-2-3-4 \\
\begin{tabular}{|l|c|c|c|c|}
\hline Variant & 1 & 2 & 3 & 4 \\
\hline Demand & 20 & 40 & 60 & 80 \\
\hline Total waiting time in buffer & \multicolumn{4}{c|}{280} \\
\hline & 1 & 2 & 3 & 4 \\
\hline & 40 & 60 & 80 & 20 \\
\hline Total waiting time in buffer & 1 & 2 & 3 & 4 \\
\hline & 60 & 80 & 20 & 40 \\
\hline
\end{tabular} \\
\hline
\end{tabular}

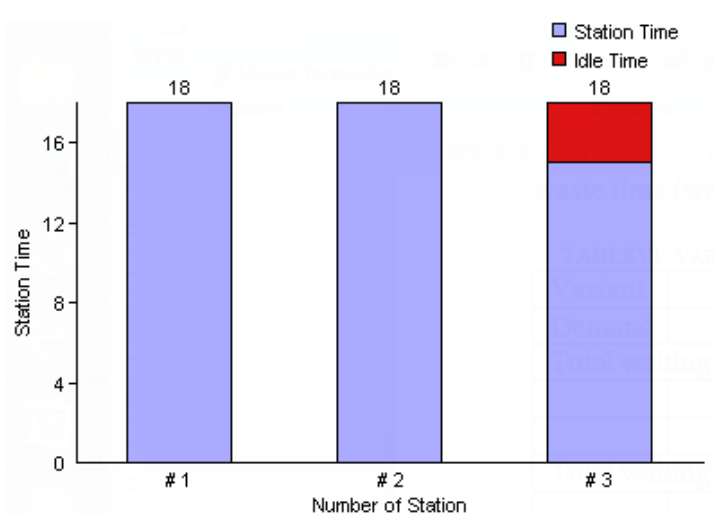

Fig. 10. Load time of each station for $c=18$ and NOF heuristic.

TABLE VII: VARIANT'S MARKET DEMAND AND TOTAL WAITING TIME FOR CYCLE TIME $C=18$ AND VARIANT'S ORDER 3-1-2-4

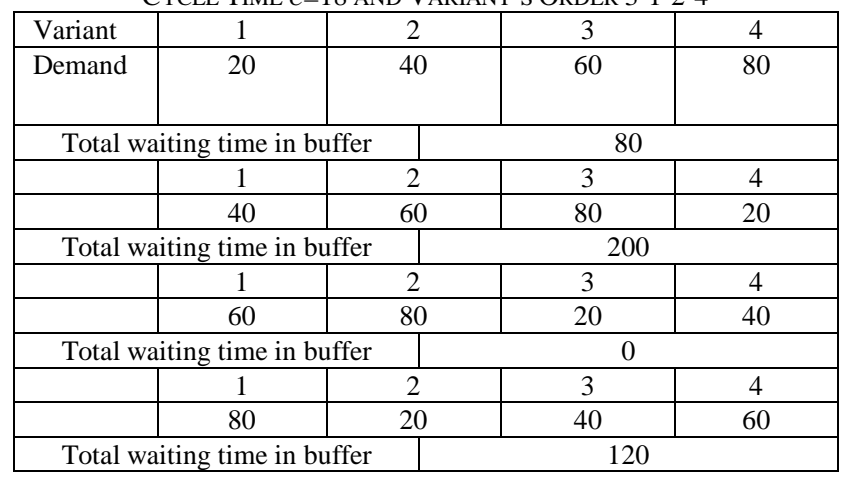

Now the workstation 1 and 2 are without idle times and the line efficiency is near $100 \%$ (94.44\%). In this case when the cycle times of assembly line structure is different than the makespan in flow shop system we need to control the order of market demand to avoid waiting time on the entrance of the assembly line (some semi products can be not ready in flow shop structure). The solution of the problem is to start with the semi product with smaller $C_{\max }(15$ and 17$)$, next to manufacture semi products with longer $C_{\max }(19)$. In our case it is the variant's order: 3-1-2-4. The total waiting times in the buffer are presented in Table VII.

\section{CONCLUSIONS AND REMARKS}

In the paper the problem of complex manufacturing system was considered. Author discussed the flow shop structure and assembly production line. The main problem is to find appropriate cycle time of the whole system. In the case when assembly line structure is the input of the system the maximum value of makespan of all variants decides about the cycle time of the assembly line and about the number of workstations. In the case when the flow shop structure is situated as the first in the complex system the steps of the calculations can be the same (first is the maximum value of the makespan (different variants) and then cycle time of the line). But the existing buffer allows for determine different cycle times of the line which differ from the maximum value of makespan. The monitoring of market demand and the order of the variants cause improving of assembly line balance what was shown in numerical example.

\section{ACKNOWLEDGMENT}

The work was supported by Grant BK 265/Rau1/ 2014.

\section{REFERENCES}

[1] R. J. Sury, "Aspects of assembly line balancing," International Journal of Production Research, vol. 9, pp. 8-14, 1971.

[2] I. Baybars, "A survey of exact algorithms for simple assembly line balancing problem," Management Science, vol. 32, pp. 11-17, 1986.

[3] E. Erel and S. C. Sarin, "A survey of the assembly line balancing procedures," Production Planning and Control, vol. 9, pp. 414-434.

[4] W. B. Halgeson and D. P. Birnie, "Assembly line balancing using the ranked positional weighting technique," Journal of Industrial Engineering, vol. 12, pp. 18-27, 1961.

[5] M. E. Salveson, "The assembly line balancing problem," Journal of Industrial Engineering, vol. 6, pp. 62-69, 1955.

[6] A. L. Gutjahr and G. L. Neumhauser, "An algorithm for the line balancing problem," Management Science, vol. 11, pp. 308-315, 1964.

[7] A. Scholl and C. Becker, "State-of-the-art exact and heuristic solution procedures for simple assembly line balancing," European Journal of Operation Research, vol. 158, pp. 666-693, 2006.

[8] A. Scholl, Balancing and Sequencing of Assembly Lines, $2^{\text {nd }}$ edition, Physica Verlag Springer Verlag Company, Germany, 1998.

[9] E. A. Süer, "Designing parallel assembly lines," Computer and industrial Engineering, vol. 35, pp. 467-470, 1998.

[10] H. Gökçen, K. Ağpak, and R. Benzer, "Balancing of assembly parallel lines," International Journal of Production Economic, vol. 103, pp. 600-609, 2006.

[11] R. G. Askin and M. Zhou, "A parallel station heuristic for the mixed-model production line balancing problem," International Journal of Production Research, vol. 35, no. 11, pp. 3095-3105, 1997.

[12] J. F. Bard, "Assembly line balancing with parallel workstations and dead time," International Journal of Production Research, vol. 27, no. 6, pp. 1005-1018, 1989.

[13] P. Pinto, D. G. Dannenbring, and B. M. Khumawala, "Branch and bound heuristic procedures for assembly line balancing with paralleling of stations," International Journal of Production Research, vol. 19 , no. 4, pp. 565-576, 1981.

[14] J. Bukchin and J. Rubinovitz, "A weighted approach for assembly line design with station paralleling and equipment selection," IIE Transactions, vol. 35, pp. 73-85, 2003.

[15] J. J. Bartholdi, "Balancing two-sided assembly lines: a case study," International Journal of Production Research, vol. 23, pp. 403-421, 1993.

[16] K. Y. Kim, W. S. Song, and J. H. Kim, "A mathematical model and a genetic algorithm for two-sided assembly line balancing," Computers and Operations Research, vol. 36, pp. 853-865, 2009. 
[17] T. O. Lee, Y. Kim, and Y. K. Kim, "Two-sided assembly line balancing to maximize work relatedness and slackness," Computers \& Industrial Engineering, vol. 40, pp. 273-292, 2001.

[18] A. Baykasoglu and T. Dereli, "Two-sided assembly line balancing using an ant-colony based heuristic," International Journal of Advanced Manufacturing Technology, vol. 36, pp. 582-588, 2008.

[19] X. Hu, E. Wu, and Y. Jin, "A station oriented enumerative algorithm for two-sided assembly line balancing problem," European Journal of Operational Research, vol. 186, pp. 435-440, 2007.

[20] W. D. He and A. Kusiak, "Designing an assembly line for modular products," Computer Industrial Engineering, vol. 34, no. 1, pp. 37-52, 1998.

[21] S. Ghosh and R. J. Gagnon, "A comprehensive literature review and analysis of the design, balancing and scheduling of assembly lines," International Journal of Production Research, vol. 27, no. 4, pp. 637-670, 1989.

[22] M. D. Kilbridge and L. Wester, "A heuristic method of assembly line balancing," The Journal of Industrial Engineering, vol. XII, no. 4, pp. 292-298, 1961.

[23] M. L. Pinedo, Scheduling Theory, Algorithm, and Systems, $3^{\text {rd }}$ Edition, Springer Verlag, 2008, ch. 6-7, pp. 151-211.

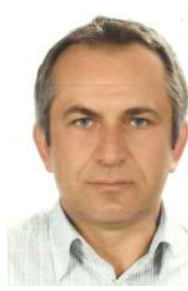

Waldemar Grzechca was born in Gliwice in Poland in 1964. He was graduated at the Silesian University of Technology in 1989 and he started to work at that time at the Department of Automation Control, Electronics and Computer Science. He focused his research on accuracy of robots trajectories and robots applications in manufacturing companies. Next he has moved his research and interest to manufacturing systems. He studied different structures of machines (sequencing and scheduling in single machine and parallel machines configurations, job shop system, flow shop system, etc.). He is especially interested in assembly lines balancing problem. He investigates different types of lines and focuses on estimation of final results of balance of single and two-sided lines. He is an author of more than 80 conference and journal papers which deals with assembly lines problems and an editor of a book titled Assembly Line Theory and Practice. In 2014 he took part in Grant of European Union BE MUNDUS in Brazil to exchange the knowledge between Polish and Brazilian universities. 